\title{
Investigating the Influence of Social Cognitive, Affective and Evaluative Identities on Participation Intention in Online Communities and Shopping (Case Study: Students of Faculty of Economic and Administrative Science, Ferdowsi University of Mashhad)
}

\author{
Toktam Vafania \\ Department of Business Management, \\ Neyshabur Branch, Islamic Azad University, Neyshabur, Iran \\ Vafaniatoktam@yahoo.com \\ Mohammad Lashkary
}

Associate Professor of Economics of Payame Noor University

Lashkarym@yahoo.com

Doi:10.5901/mjss.2015.v6n3s2p732

\begin{abstract}
Previous studies show that there are many researches about online communities. Increasing in participating in online tasks, which lead to E-shopping, that lead to better marketing strategy and more profit is the cause of this research. Thus, the aim of this research is to investigate the influence of social, cognitive, emotional and evaluative identity on participation intention in online communities and shopping. We have 6 hypotheses through reviewing the literature from 1995 until 2013. The results show that social, cognitive, emotional and evaluative identity has significant impact on online space.
\end{abstract}

Keywords: social cognitive, affective and evaluative identity, participation intention in online space.

\section{Introduction}

In recent years, the rapid development of information and communication technologies have a significant impact on human life and the functioning of organizations and institutions in various countries. According to the experts, as the invention of the steam engine and the industrial revolution make a huge change in personal life and job created, the communications revolution has also brought its own changes (Zhou, 2011, 68). Because there are a variety of informational and social media, the world has become a village where information and media systems and components are connected to each other. Information and communication technology are a wide range of technologies such as the Internet, satellite, cell phone, cable TV and home computers and video that send and receive all types of, verbal, audio and video messages and distribute, product, store information for communication between people. Online communities is a portion of Internet users despite the participation of online users in a virtual space, this participation depends on individuals and groups. Thus some people do not like to participate in online space. (Bishop-2007, 1882).

Since the advent of information and communication technologies, researchers examine the consequences of using these technologies extensively from different perspectives. Accepting information technology is a multidimensional phenomenon and includes a wide range of key variables such as perceptions, beliefs, attitudes and characteristics of individuals and their involvement with information technology (Chung Chi Cheung, 2001, 10).

User acceptance is defined as a tendency between a group in order to use information technology and communication for doing some tasks .

In the past two decades, several models and theories in the field of technology adoption have been proposed, tested and modification that are originated in psychology and sociology. These models help to recognize factors that facilitate technology adoption by users (Sun and Zhang, 2006, 54). These models are described below. 


\section{Theory and Models of ICT Accepting}

\subsection{Technology Accepting Model}

Among the various patterns that IT researchers use to explain or predict the motivational factors (which applies to technology acceptance by users) Davis \& associates technology acceptance model, is one the most commonly used models in this area. This model is based on this idea that people's subjective perceptions of the technology would influence their attitudes about technology (Lee and Kim, 2009, 192). This model asserts that using information and communication technologies depends on perception of easiness in use (Walter and Lopez, 2008, 207).

As figure 1 show, using information and communication technologies has 4 stages:

- External variables influence the opinions of users to use ICT.

- User opinions effect on their attitude to the use of information and communication technologies.

- Use opinions influence their willingness to use ICT.

- User'stendency to use ICT determines the level of use (Burton-Jones\& Hubona, 2006, 707).

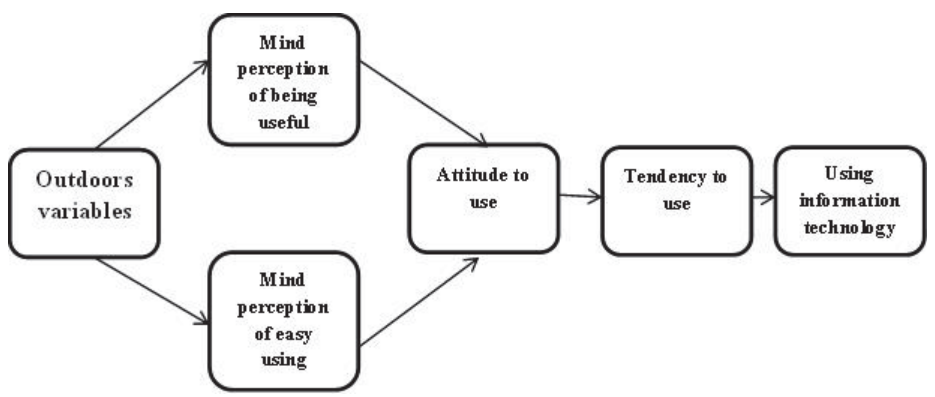

Figure1. Model of using information technology(Burton-Jones\&Hubona, 2006, 707).

Technology acceptance model is a model that is based on the desire and expresses willingness to accept technology is a good predictor for the actual use of the technology (Hong, Tung TC, 2006, 1820) and it can be used to predict behavior before using information and communication technologies.

Willingness to acceptance is the attitude of a person to perform a particular behavior that is a major factor in the actual doing of the act.

This model comes from the theory of reasoned action (TI TR) as a framework for predicting and explaining human behavior. The theory of reasoned action determines the causal relationships in the movement of ideas, attitudes and behavioral dispositions. Technology acceptance model, which is a modified form of the theory of reasoned action, is used to predict Accepting ICT by replacing the key or beliefs variables Figure 1.

The reasoned action theory includes two key items: perception of usefulness and perception of easiness. Moreover, in this model, perception of easiness influence directly on perception of usefulness and external variables effect on perception of usefulness. Moreover, external variables that directly influence on perception about usefulness and easiness may be significant factors in technology acceptance model that include ICT features and personal attributes and environmental variable it is considered that this model is an acceptable model between different researchers the weakness of this model is lack of considering social factors that have a great influence in people attitude for accepting technology. In order to cover this weakness, some other factors such as social effects process like imagination and voluntary and also instrumental process of cognitive like product quality and job importance have been added to the model (Yu, Li, \& Gagnon, 2008, 521). Social effects and cognitive instrumental process have significant effect on ITC acceptance (Yu; Ha, Choi, \& Rho, 2005, 968).

\subsection{Examining theories of consumer behavior}

\subsubsection{Theory of planned behavior}

Theory of planned behavior is used in many fields such as accepting of information and communication technologies. 
This theory, which is presented by Armitage \&Conner (2001) and Grizzell (2007), asserts that behavior depends on personal intention. Intention determines attitudes and norms. Moreover, behavior is under the effect of perceived behavioral control. There is relationship between these factors and all of them are under the influence of environment, which is shown in figure 2 .

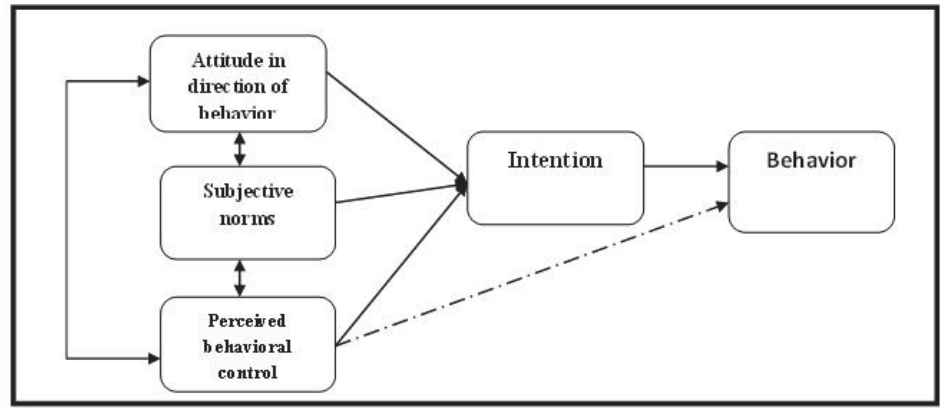

Figure 2. The theory of planned behavior

Gudin and Kooc (1995) express that intentions are the most important factor in forming behavior. Perceived control has relationship with self-confidence. Thus, sources, opportunities and skills are the important factors of change process. Motivational factors are used for prediction behavior in this model. According to this theory, intention obtained from attitude, norm and perception of behavior control (Chen, Fan, \& Farn, 2007, 304). It is considered that behavior stimulates by willingness and this willingness is determined by person attitude toward behavior, norm and ability to success. The attitude of a person about a behavior is a desirable or undesirable feeling that obtained from people believes. In other words, the attitude is the assessment or evaluation of the desirability or undesirability of a behavior (Fang, Shao and Lan, 2009, 148- 150).

Norm believes and motivation for following of reference groups lead to form mental norm. Mental perception of behavior control shows the person perception of opportunities and sources. In other words, perceived behavioral control means that internal and external resources will limit the occurrence of a behavior (Yi et al, 2006, 353). Generally, the more positive attitude and subjective norm is desirable a person tends to be more robust behavior. Under the guidance of behavior theory individual differences in perceived behavioral control directly affects the use of information and communication technology.

Training and experience have direct and positive impact on their use of ICT (Burton-Jones and Hubona, 2006, 710).

\subsubsection{Social Cognitive Theory}

Social change model of Bandura (1986) suggests that people motivate not only by internal factors, but also by foreign forces. This change model proposes that human behavior is influenced by a combination of environmental, personal and behavioral factors. This interaction is shown in Figure 3.

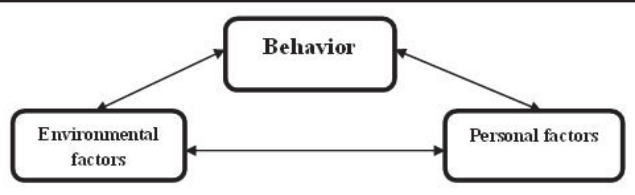

Figure 3. Social cognition model (Bandora 1986)

Environmental factors cause a condition that can affect the behavior shaping. While personal factors include drivers, actuators, and motivation. According to this theory some key factors affect behavioral change such as self-confidence: the degree to which a person is confident in their abilities and skills. Expectations of outcomes: the degree to which a person expects the behavior has appropriate outcome. Finally, internal control that is the degree to which a person can 
control his behavior and amplifiers that increase or decrease risk factors that lead to the behavior. To increase confidence in the people, the necessary resources and support to individuals have to be provided. While Prry et al (1990) argue that to build confidence in people small steps should be taken to change behavior. Bandura (1986) believes that we need motivations to change behavior. Managers should identify the environmental factors that impede behavior change as well as providing social support for persons act.

\subsubsection{Model of "expectation- confirmation"}

Since the early 1970s, several attempts have been made to study consumer behavior processes after purchasing a product. Expectation-confirmation paradigm is used to explain consumer satisfaction and decision to re buy. This paradigm focuses on mental motivation after accepting ICT. (Kang; Hong, \& Lee, 2009, 116).

According to the majority of studies that have used this paradigm, decisions related to consumer satisfaction are made with regard to two important components include the initial expectations (expectations before purchase) about a product or service and the difference between expectations/ performance, products and services. Based on this model, buyers first have expectation from product then experience of the product forms their mental expectancy from performance and finally, a comparison of perceived performance and its reference frame (expectations), confirm or reject the expectations. Once a product has been worse than expected purchase expectation is negative and when it is more than is expected it is positive. Satisfied consumer continue to use products or services (Premkumar \& Bhattacherjee, 2008 , 48). This model is based on expectation paradigm for using ICT continuously. As figure 4 displays, this model predict user's intention based on 3 items:

1- The degree of IT acceptance

2- Users' expectancy after accepting ICT. Expectation is a set of believes about attributes of a product (Hong et al, 2006, 1824). Two expectations have been added to expectations after model acceptance include: enjoyableness and easiness (Kang et al, 2009, 126). Perception about enjoy referred to the degree of enjoy of ICT.(Kim; Choi, \& Han, 2008, 1538).

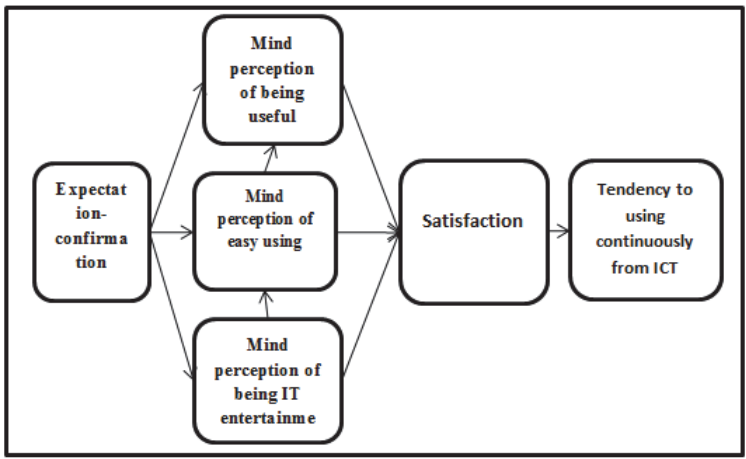

Figure 4. Model of using continusly information and communication(Kim; Choi, \& Han, 2008).

\subsection{Social identity of person}

Tajfel (1972) asserted that social identity is a part of person which is obtained from knowledge and experience in a social group as well as feelings. Social identity is the feeling that people have about themselves. In fact, Albert and colleagues (1998) have suggested that individuals have a sense of pride of belonging to a social group as well as the interaction with other people. People spend a lot of time thinking about how to handle their own future: how and when to ask for money from the father or mother. How to enter to the party, and so on. Moreover, the perception of people about how audiences react to the behavior of their hypothetical behavior is integral part of the process. Hence, other people (whether real or imaginary) are part of the content constitute their social identities. But people are always strictest critic (Azdanlo, 1388, 682). In fact, cognitive social identity helps people find their way to change his place by others place in a society where people define themselves by membership in a social system. (Johnson and Morgeson, 2008, 352).

Social identity is not merely a day dream. They are the source of action. They provide criteria for evaluating real behaviors. Identity needs to find a foothold in the international community. But, in any case, social identities are fragile. 
Because they tend to be ideal and are often in conflict with reality. There is no guarantee that others accept what a person wants to inspire. Therefore, one of the main goals of social interaction is the creation and maintenance of social identity. Identity depends on the perceptions of others and others perception is needed for establishment of identity. The original meaning of identity is similarity and difference. One's social identity is never finished and is always subject to change and revision (Azdanlo, 1388, 682).

\subsection{Online community}

In 2008, a report was published which asserts nearly a third of adults have extra time to spend online and are using online technologies. Also, for example, Facebook has more than 175 million users internationally, which can be considered as the sixth largest country in the whole wide world. (Harrison and Thomas. 2009, 125). Elison (2007) defined online communities as follows:

Creating a profile or something similar to profiles that is limited within a system.

Creating a list of peoples that interact with each other.

Moreover, people that have relationship with people in or out of the online social system.

Online communities increasingly are acceptable part of everyday life in which all human beings have the inherent desire to help and interact with others. These communities have different forms (Bishob, 2003, 1884). Such communities often have been provided by groups of people who are willing to share interests, goals and their values. Many online communities are concerned the dilemma of losing their members and non-members and the absence of viability and stability. Researches show that there are many reasons for not participating in online communities. Preece, Nonnecke, and Andrews (2004) mentioned that some people do not like to share something in a group. For example, Facebook creates a space in which people could interact together and share their information ( Thomas and Harrison, 2009,658)

\section{Conceptual Model}

This model that is based on Zhou model (2011) has 3 independent variables include Cognitive, evaluative and affective identity. Participation intention is final variable.

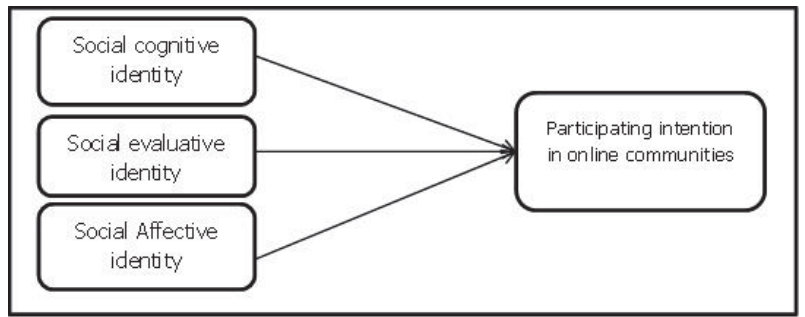

Figure 1. Conceptual model (Zao 2011)

\subsection{Hypotheses}

1- Social cognitive identity has significant impact on participating intention in online communities.

2- Social evaluative identity has significant impact on participating intention in online communities.

3- Social Affective identity has significant impact on participating intention in online communities.

\section{Methodology}

This is a survey - analytical study because determines the relationship between variables and it is a prescriptive and practical study. Sample consists of all students in levels of associated, bachelor, master and PhD level.

\section{Validity and Reliability}

Face and content validity were examined in two stages, as well as confirmatory factorial validity was examined. Golfeshani (2003) defined reliability as the extent to which the results are consistent over time. According to Field (2006), 
Cranach's alpha measure the validity that is one of the most popular tools in behavioral research and the accepted value is at least 0.7 . this coefficient is shown in table 1 . This value for questioner was more than 0.74 which display the validity.

Table 1. Cronbach a values

\begin{tabular}{|l|c|c|}
\hline Variables & Number of questions & Cranach $\boldsymbol{\alpha}$ \\
\hline cognitive identity & 3 & 0.82 \\
\hline Affective identity & 3 & 0.78 \\
\hline evaluative identity & 3 & 0.90 \\
\hline Participating intention & 2 & 0.80 \\
\hline Total & 15 & 0.74 \\
\hline
\end{tabular}

\section{Demographic View}

Table 2. Demographic view

\begin{tabular}{|l|c|c|c|c|}
\hline Characteristics & Responds & Frequency & Frequency percent & Cumulative frequency percent \\
\hline \multirow{3}{*}{ Sexuality } & women & 147 & $75 \%$ & 75 \\
\cline { 2 - 5 } & man & 49 & $25 \%$ & 100 \\
\hline \multirow{4}{*}{ Education level } & Resource & 5 & 6.2 & 6.2 \\
\cline { 2 - 5 } & Bachelor & 96 & 49 & 55.2 \\
\cline { 2 - 5 } & Masters & 92 & 9.46 & 64.66 \\
\cline { 2 - 5 } & PHD & 3 & 1.5 & 400 \\
\cline { 2 - 5 } & 18 to 22 & 79 & 40.3 & $88.3 \%$ \\
\cline { 2 - 5 } & 22 to 26 & 95 & 48.5 & $95.7 \%$ \\
\hline \multirow{n}{*}{$\begin{array}{l}\text { Frequency of using } \\
\text { services in one month }\end{array}$} & 26 to 30 & 18 & 9.2 & $100 \%$ \\
\cline { 2 - 5 } & Higher than 30 & 4 & 2 & $20.9 \%$ \\
\cline { 2 - 5 } & Less than 3 times & 41 & 20.9 & $42.3 \%$ \\
\cline { 2 - 5 } & $3-6$ times & 42 & 21.4 & $47 \%$ \\
\hline
\end{tabular}

\section{Hypotheses test}

T test has been used for hypotheses $\mathrm{H} 0$ and $\mathrm{H} 1$.

First hypothesis: social affective identity impact on the intention to use of the internet and online shopping.

$\mathrm{HO}$ : The mean of the variable of interest $=3$

$\mathrm{H} 1$ : The mean of the variable of interest $\neq 3$

Table 3. Descriptive statistics of affective identity

\begin{tabular}{|c|c|c|c|c|}
\hline Standard error & Standard deviation & Average $(\bar{x})$ & Number & $\begin{array}{c}\text { Index } \\
\text { Variable }\end{array}$ \\
\hline 0.06 & 0.83 & 2.37 & 196 & Affective identity \\
\hline
\end{tabular}

Table 4. One-sample t-test.

\begin{tabular}{|c|c|c|c|c|c|c|}
\hline \multicolumn{6}{|c|}{ Test Value $=3$} & \multirow{3}{*}{ variable } \\
\hline \multicolumn{2}{|c|}{ Confidence interval (95\%) } & \multirow{2}{*}{ Result of hypothesis } & \multirow{2}{*}{ P_Values } & \multirow{2}{*}{ Df } & \multirow{2}{*}{$t$} & \\
\hline Higher level & Lower level & & & & & \\
\hline-0.7428 & -0.6258 & confirmed & 0.001 & 195 & -10.556 & Affective identity \\
\hline
\end{tabular}

The results are shown in above table. As it is seen, significance level is 0.001 that is lower than 0.05 .Also, as shown in Table 4, given that the p-value is smaller than the $5 \%$ (significance level), then $\mathrm{HO}$ is rejected. And given that the average value calculated for affective identity (2.37) is lower than 3,thus,affective identity is smaller than 3 and therefore the null 
hypothesis is rejected.Finally, null hypothesis is rejected with $95 \%$ confidence and the contrary is confirmed. Thus, affective identity impacts on the Internet and online shopping intention.

Second hypothesis: social cognitive identity effect on intention to use the Internet and online shopping.

$\mathrm{HO}$ : The mean of the variable of interest $=3$

$\mathrm{H} 1$ : The mean of the variable of interest $\neq 3$

Table 5. Descriptive statistics of cognitive identity

\begin{tabular}{|c|c|c|c|c|}
\hline Standard error & Standard deviation & Average $(\bar{x})$ & Number & Index \\
\hline 0.06 & 0.81 & 3.47 & 196 & Variable \\
\hline
\end{tabular}

Table 6. One-sample t-test

\begin{tabular}{|c|c|c|c|c|c|c|}
\hline \multicolumn{6}{|c|}{ Test Value $=3$} & \multirow{3}{*}{ variable } \\
\hline \multirow{2}{*}{\multicolumn{2}{|c|}{ Confidence interval (95\%) }} & Rocoult of hynathecis & P Valune & $\mathrm{Df}$ & $t$ & \\
\hline & & Resunit or mypotilesis & r_values & Di & $l$ & \\
\hline 0.6519 & 0.46599 & confirmed & 0.001 & 195 & 8.056 & cognitive identity \\
\hline
\end{tabular}

Third hypothesis: Social evaluative identity influence on intention to use the Internet and online shopping.

$\mathrm{H} 0$ : The mean of the variable of interest $=3$

$\mathrm{H1}$ : The mean of the variable of interest $\neq 3$

Table 7. Descriptive statistics of evaluative identity

\begin{tabular}{|c|c|c|c|c|}
\hline Standard error & Standard deviation & Average $(\bar{x})$ & Number & Index \\
\hline 0.06 & 0.82 & 2.14 & 196 & Variable \\
\hline
\end{tabular}

Table 8. One-sample t-test

\begin{tabular}{|c|c|c|c|c|c|c|}
\hline \multicolumn{6}{|c|}{ Test Value $=3$} & \multirow{3}{*}{ variable } \\
\hline \multicolumn{2}{|c|}{ Confidence interval (95\%) } & & & $D f$ & $t$ & \\
\hline Higher level & Lower level & Result of hypothesis & P_Values & UT & $\tau$ & \\
\hline-0.97 & -0.86 & confirmed & 0.001 & 195 & -14.71 & evaluative identity \\
\hline
\end{tabular}

The results are shown in above table. As it is seen, significance level is 0.001 that is lower than 0.05 . Also, as shown in Table 4, given that the p-value is smaller than the $5 \%$ (significance level), then $\mathrm{H} 0$ is rejected. And given that the average value calculated for evaluative identity (2.14) is lower than 3,thus, affective identity is smaller than 3 and therefore the null hypothesis is rejected. Finally, null hypothesis is rejected with $95 \%$ confidence and the contrary is confirmed. Thus, evaluative identity impacts on the Internet and online shopping intention.

\section{Conclusion and Discussion}

The first hypothesis about the impact of affective identity impact on online shopping intention was confirmed. The result of this hypothesis is compatible with the studies of Zhou et al (2011), Zhang et al (2008), Wu et al (2010), Pentina et al (2008), and Zhou et all (2007). In all these studies, the main point is that the concept of social affective identity, sense of belonging and a desire to connect with others, influence on the intention to participate in the community and shopping Internet.

The theory of commitment by Bateman et al (2010) proposed and expresses three types of affective commitment, normative and continuous commitment impact on user behavior, the result supports the hypothesis. Thus, the result asserts that social factors have significant effect on acceptance of ICT.

The second hypothesis of this study examined the social cognitive identity and intention to participate in the online shopping space, which has been confirmed by the error 0.05. it is confirmed with Bagozzi \& Dholakia (2002), Dholakiaet 
al (2004), and Zhou and colleagues (2011). The Gupta and Kim (2004) asserts that customer commitment to the online community and virtual belief comes from balance between the two major factors of beliefs (perceived usefulness, functional, system usefulness, system quality) and emotion (feelings of pleasure and arousal). The result of the study was consistent with the results of the present hypothesis. Because it is expressed that function of other factors such as social and interpersonal factors than systemic factors influence the acceptance of information technology and online community. Thus, when people like to identify themselves as another people and with another identity they are more likely to use internet and participate in online community. Aizhen Loh (2011)mentioned in their study about the effects of trust and social identity in the process of decision-making and participation in online networks that social identity has an impact on participation in the online space which is compatible with the hypothesis.

The third hypothesis of this study examined the impact of social evaluative identity on intention to participate in the online shopping space, which has been confirmed by the error 0.05 . Thus, social evaluative identity that expresses the concept that how a person introduces himself with social treatment has impact on their use of the Internet and online shopping. The result of these assumptions is consisting with the studies of Aizhen Loh (2011), Bagozzi \& Dholakia (2002), Zeng and colleagues (2009), Harrison Walker (2010) and Goitty et al (2010). All of these researchers have studied consumer behavior in online communities. Moreover, HSU and Lu (2005) examined consumer behavior in online game communities. So, users' loyalty arouse by social norms. So in this study the fact that social norms that include social evaluative identity influence on user participation in community planning and shopping online.

\section{Practical Suggestions}

According to the confirmation of hypothesis 1 , it is suggested that online community designer focus on factors such as perceived usefulness and perceived ease of use as well as social factors and influence on people social identity through providing better quality of service and system and more information.

According to hypothesis 2 it is recommended that online system designers use appropriate patterns to increase user's awareness in order to increase their cognitive identity. This can be done through E-mail and hyperlinks.

Given hypothesis 3 , it is suggested that designers provide more qualified information and virtual space in order to increase commitment and loyalty of users.

Finally, it is suggested that managers focus on social factors such as cognitive, evaluative and affective identities and mental norms in order to increase social identity, loyalty and commitment of users, which leads to online purchase increase and profit.

\section{References}

Armitage, C., \& Conner, M. (2001). Efficacy of the theory of planned behaviour: A meta-analytic review. British Journal of Social Psychology, 40, 471-499.

Bishop.J. (2007). Increasing participation in online communities: A framework for human-computer interaction, Computers in Human Behavior 23 (2007) 1881-1893.

Burton-Jones, A. \& Hubona, G.S. (2006). The Mediation of External Variables in the technology Acceptance Model. Information \&Management, 43, 706-717.

Chang, K.M., Cheung, W. (2001). Determinants of the Intention to Use Internet at Work: a Confirmatory Study Information and Management, 39 (1), 1-14.

Chen, C.D.; Fan, Y.W \& Farn, C.K. (2007). Predicting Electronic Toll Collection Service Adoption: An Integration of the TechnologyAcceptance Model and the Theory of Planned Behavior.

Dillon, A., Morris, M. G. (1996). User Acceptance of Information Technology: Theories and Models. Annual Review of Information Science and Technology, 31, 3-32.

Fang.J, Shao.P and Lan, G. (2009). Effects of Innovativeness and Trust on Web Survey Participation. Computers in Human Behavior, $25,144-152$.

Gefen, D., Karahanna, E. and Straub, D.W. (2003), "Trust and TAM in online shopping:

Grizzell, J. (2007, 1/27/2007). Behavior Change Theories and Models. Retrieved January 28, 2007, from http://www.csupomona.edu/ jugrizzell/best_practices/bctheory.html.

Hong, S.J.; Thong, J.Y.L. \& Tam, K.Y. (2006). Understanding Continued Information Technology Usage Behavior: A Comparison of Three Models in the Context of Mobile Internet, Decision Support Systems, 42, 1819-1834.

Kang, Y.S.; Hong, S. \& Lee, H. (2009). Exploring Continued Online Service Usage Behavior: The Roles of Self-Image Congruity and Regret.Computers in Human Behavior, 25,111-122.

Kim. B.; Choi, M. \& Han, I. (2008). User Behaviors toward Mobile Data Services: The Role of Perceived Free and Prior Experience. Expert Systems with Applications, 34,4. 
Lee, S. \& Kim, B.G. (2009). Factors Affecting the Usage of Internet: A Confirmatory Study. Computers in Human Behavior, 25, $191-201$.

Lorin, M. H. \& Erick, B. (1997). Information Technology and Internal Firm Organization: An Exploratory Analysis. Journal of Management Information Systems, Vol. 14, No. 9, 81-84.

Perry, C. L., Barnowski, T., \& Parcel, G. S. (1990). How individuals, environments, and health behavior interact: Social learning theory. In K. Glanz, F. M. Lewis \& B. K. Rimer (Eds.), Health Behavior and Health Educaiton: Theory Research and Practice. San Francisco, CA: Jossey-Bass.

Premkumar, G. \& Bhattacherjee, A. (2008). Explaining Information Technology Prentice-Hall, Englewood Cliffs, NJ.

Sun, H. \& Zhang, P. (2006). The Role of Moderating Factors in User Technology Acceptance. Int. J. Human-Computer Studies, 64, 5378.

Walter.z and Lopez, M.S. (2008). Physician Acceptance of Information Technologies: Role of Perceived Threat to Professional Autonomy. Decision Support Systems, 46, 206-215.

Yi, M.Y.; Jackson, J.D.; Park, J.S. \& Probst, J.C. (2006). Understanding Information Technology Acceptance by Individual Professionals: Toward an Integrative View. Information \& Management, 43, 350-363.

Yu, J.; Ha, I.; Choi, M. \& Rho, J. (2005). Extending the TAM for TCommerce. Information \& Management, 42, 965-976.

Yu, P.; Li, H. \& Gagnon, M.P. (2008). Health IT Acceptance Factors in Long-Term Care Facilities: A Cross-Sectional Survey. Int. J. Medical Informatics, 78 (4). 